\title{
Bone graft materials for current implant dentistry
}

\author{
Keunyoung Jang ${ }^{1}$, Jong-Ho Lee ${ }^{2}$, Sung-Hwan $\mathrm{Oh}^{3}$, Byung-Do Ham ${ }^{4}$, Sung-Min Chung ${ }^{5}$, \\ Jeong Keun Lee, , Jeong-Kui Ku ${ }^{7,8}$
}

${ }^{1}$ Seoul Highan Dental Clinic, Seoul, ${ }^{2}$ Department of Oral and Maxillofacial Surgery, Oral Cancer Center, Clinical Trial Center, Seoul National University, School of Dentistry, Seoul, ${ }^{3}$ Dr OH's Healing Dental Clinic, Jeonju, ${ }^{4}$ Kainos Dental Clinic, Seoul, ${ }^{5}$ Well Dental Clinic, Seoul, ${ }^{6}$ Department of Oral and Maxillofacial Surgery, Institute of Oral Health Science, Ajou University School of Medicine, Suwon, 'Department of Oral and Maxillofacial Surgery, Section of Dentistry, Armed Forces Capital Hospital, Seongnam, ${ }^{8}$ Department of Oral and Maxillofacial Surgery, Seoul Asan Medical Center, Seoul, Korea

In 2018, the Autumn conference of the Korean Academy of Implant Dentistry presented a lecture on the latest knowledge on bone grafts for implant dentistry. The author summarized the characteristics, advantages, and limitations of four typical bone graft materials, which are autogenous bone graft, autogenous tooth derived bone graft, xenograft, and alloplastic graft material. In addition, this study suggested the theoretical background through a literature review on bone graft surgery in current implant dentistry. (JOURNAL OF DENTAL IMPLANT RESEARCH 2020;39(1):1-10)

Key Words: Bone substitute, Dental implant, Dentistry

\section{INTRODUCTION}

Many different types of bone graft materials are available commercially, but there is still controversy as to the most suitable type for clinical practice. Although it has been nearly 50 years since the introduction of bone grafts in implant dentistry, it is difficult to establish a single gold standard material or technique because of anatomical variations, cost effective treatment options, various clinical situations, and technological advances. The selection process for the most appropriate type of bone graft material to use would depend on the systemic general condition, operation site, and socioeconomic conditions. In particular, the preference and experience of the surgeon appears to have a significant influence. For example, in any periodontal defect, the technical choice for guided bone regeneration (GBR), which is the most commonly used procedure, may be consistent. On the other hand, the material choice, such as the selection and combination of types (autograft, allograft, xenograft, and allo- plast), can differ according to the surgeon. Therefore, it would be difficult to suggest a "gold standard" for every case. Instead, there is a "standard protocol" for each clinician that integrates their individual knowledge and experience. The fact that good results are obtained despite the various methods is interesting.

For this reason, the Korean Academy of Implant Dentistry (KAID) invited four Korean clinicians to hold a conference on "Bone grafts for implant dentistry" in October 7, 2018. They discussed and suggested their standard protocol and preferred graft materials. This consensus paper summarizes the lecture contents and complement the theoretical background through a literature review for past, present, and future graft materials in implant dentistry ${ }^{1)}$.

\section{AUTOGENOUS BONE GRAFT}

As implant treatments become the first option for edentulous patients, many methods of implantation have been developed for various alveolar defects. Until now,

Received September 28, 2019, Revised January 2, 2020, Accepted January 3, 2020.

(c) Journal of Dental Implant Research.

(i) This is an open access article distributed under the terms of the Creative Commons Attribution Non-Commercial License (http://creativecommons.org/licenses/by-nc/4.0) which permits unrestricted non-commercial use, distribution, and reproduction in any medium, provided the original work is properly cited.

Correspondence to: Jeong-Kui Ku, Department of Oral and Maxillofacial Surgery, Section of Dentistry, Armed Forces Capital Hospital, 81 Saemaul-ro 117 , Seongnam 13634, Korea. Tel: +82-31-725-6184, Fax: +82-31-706-0987, E-mail: kujk123@gmail.com 
however, the gold standard is the method using autogenous bone ${ }^{2)}$. Vertical and horizontal distraction osteogenesis can be one of the predictive treatment options and a Lefort I osteotomy can be performed simultaneously in the maxilla in the severe jaw discrepancy cases. Among the graft materials, autogenous bone is the only material with all characteristics of a bone graft, such as releasing growth factors, osteoconduction, osteoinduction, and osteogenesis ${ }^{2}$. Particulate type autologous bone grafts are relatively easy to harvest but require an additional technique for the stabilization of particulate type, autogenous bone grafts. On the other hand, although block type autogenous bone is easy to manipulate at augmentation, it is difficult to collect. Moreover, the bone implant contact ratio (BIC) at the initial stage of implantation is favorable with a veneer or onlay-type block bone graft in implant dentistry ${ }^{3)}$.

Different surgeons in various hospitals have performed unilateral ramal bone harvest for moderate to severe atrophy or defects involving one to four teeth. Iliac bone harvests have been selected for further severe defects or atrophy of the jaw ${ }^{4}$.

Of the 216 patients who underwent ramal harvesting, about $15 \%$ had the subjective feeling of sensory disturbances immediately after surgery but no cases were observed after six to nine months. Donor site infection occurred in less than $10 \%$ of the patientswith inadequate drainage after surgery and around $6 \%$ had wound dehiscence. In 49 patients who underwent an iliac harvest, an average of 8 days of gait disturbance was observed in $24 \%$ of patients. Both ramus and iliac harvests had no permanent or serious donor site complications. In the recipient site, there were also mild complications with less than $10 \%$ with wound dehiscence, with graft removal due to infection, and with partial graft failure ${ }^{5)}$.

When performing a 1-stage procedure with autogenous block bone graft, the path and position of the implant could be selected more accurately considering the location of the block bone and screws, but there might be unexpected resorption around the implant. Implantation after a graft is better as a possible delay for BIC because the grafted bone remained without remodeling even after 9 months of an autogenous graft ${ }^{6}$. On the other hand, the 2-stage procedure could be used for implantation under clinical stable conditions at 4 to 9 months after the autologous bone graft.

Autogenous bone has been controversial because it tends to be absorbed after a graft. Many studies have reported resorption rates of between 0 and 25\% ${ }^{7-10}$. Cordaro et al. ${ }^{7)}$ reported that up to $42 \%$ were resorbed vertically 6 months after transplantation. Similar to previous studies, there was an average 30\% volume change at 1 year after the implantation of 97 implants and grossly $1 \mathrm{~mm}$ and $2 \mathrm{~mm}$ of marginal bone loss were observed after 1 and 13 years, respectively. According to the 1-stage and 2-stage procedures, there were no differences until the first year but a significant difference in marginal bone loss was observed between the 1-satge and 2-stage procedures 6 years after the graft: $1.8 \pm 1.3 \mathrm{~mm}$ and $1.3 \pm 0.6$ $\mathrm{mm}$ for the 1-stage and 2-stage procedures, respectively. The onlay and veneer-type block bone graft were showed $0.8 \pm 1.1 \mathrm{~mm}$ and $0.9 \pm 0.7 \mathrm{~mm}$ of marginal bone loss, respectively, at the first year and $2.1 \pm 1.1 \mathrm{~mm}$ and $1.3 \pm 0.6$ $\mathrm{mm}$ at 10 years after graft, respectively ${ }^{9}$. A similar result was reported in 2007 in that most marginal bone loss occurred in the first year. In addition, it appears to be a successful outcome based on the 2015 study, in which the progression of peri-implant bone loss was reported to be associated with marginal bone loss $(>2 \mathrm{~mm}$ at the initial 18 months or over $0.44 \mathrm{~mm}$ per year) ${ }^{12}$.

In 2007, Levin et al reported an $88 \%$ 5-year cumulative survival rate of 129 implants that had been installed at an average of $5.2 \pm 1.1$ months after the ramal block bone graft $^{13)}$. In 2014, Schwartz-Arad et al reported an $83 \%$ 11.5-year cumulative survival rate of 633 implants that were installed at an average of $4.5 \pm 2.6$ months after the ramus block bone graft $^{14)}$. Despite the relatively unsuccessful long-term implant survival rate with a block bone graft, 97 implants with a ramus block bone graft in this survey showed a 5-year, 10-year, and 13-year cumulative survival rate of $95.8 \%, 93.8 \%$, and $93.8 \%$, respectively, after implantation. An $82 \%$ survival rate was observed in 23 implants with 1-stage procedure and $94.3 \%$ survival rate of 166 implants with the 2-stage procedure after an average of 6.4 months after the iliac bone graft. The overall survival rate of 189 implants with an iliac block bone graft was $92 \%$ at 10 years after implantation, which was significantly higher than in pre- 
vious reports without a difference between the ramus and iliac block bone ${ }^{8}$.

Therefore, an autogenous block bone could be used reliably to improve the horizontal and vertical conditions for implant placement in moderate to severe jaw atrophy or defects. Some studies have shown that marginal bone loss of the implant would occur due to the resorbed tendency of grafted autogenous bone, but there was a successful long-term follow-up result in terms of the implant success criteria because of the low marginal bone loss and high survival rate.

\section{AUTOGENOUS TOOTH DERIVED BONE GRAFT}

Autogenous tooth-bone graft materials (ATBG) are being used increasingly in Korean implant dentistry. Nevertheless, the materials and procedures need to be reviewed at the KAID level. Before the review of ATBG, "good bone graft materials" have the following characteristics: 1) capacity of revascularization; 2) osteoconduction, osteoinduction, and angiogenesis ability; 3) density and remodeling of grafted bone matrix; 4) infection resistance; 5) cost-effective; and 6) easily handling. Among them, the most important ability of a graft material would be angiogenesis and osteogenesis, and 'good graft materials' might be dependent on the reproducibility of these features ${ }^{15)}$. As a result, the long-term outcome might also be good if the graft becomes healthy tissue that resists wound dehiscence and infection with early stabilization and epithelization. Because the histology of all cases could not be confirmed clinically, it is very important to use any material as a bone graft for dental implants.

Autogenous bone, which has been regarded as the gold standard for a long time, has excellent osteogenesis and infection resistance. On the other hand, it is difficult to harvest autogenous bone in all cases and volume reduction is inevitable at long term follow-up. Generally, in the case of xenogenic bone graft material used widely in clinical practice, sufficient bone formation can occur under favorable regeneration conditions, such as socket preservation or sinus lift $^{16)}$. Despite extensive vertical and/or horizontal augmentation being performed, it was unclear if bone formation had actually progressed to the end despite sufficient volume being maintained. In addition, in the case of a sinus graft, infections could not be treated until complete removal of the xenograft ${ }^{17)}$. This vulnerable characteristics of infection could also be a problem in the peri-implantitis patient ${ }^{17}$. This section discusses the use of ATBG, which has been complemented for the weaknesses characteristics.

The effects of using ATBG as a graft material have been reported ${ }^{18-20)}$. The use of teeth as graft materials, which was regarded as waste, was initially unfamiliar. On the other hand, there is evidence of the good properties of teeth as a bone substitute material ${ }^{18-20)}$. An analysis of the component showed that teeth have a high mineral content ( $75 \%$ of mineral, $20 \%$ of organic included $90 \%$ of type I collagen, $5 \%$ of water) compared to bone $(45 \%$ of mineral, $35 \%$ of organic included $90 \%$ of type I collagen, $20 \%$ of water $)^{18)}$. This means that the proportion of fat marrow and collagen in tooth tissue is low and high, respectively. Therefore, ATBG can be regarded as a bone substitute material composed of excellent collagen. In addition, ATBG gave a rigid form of tissue regeneration and had high infection resistance. The material could be produced in block or particulate form according to the processing methods and application. Moreover, organic substances, such as bone morphogenic protein (BMP), have osteoinductive capacity $^{19}$. In an animal experiment study, the osteogenic action of particulate dentin was reported $^{20)}$, which could be expected to have a similar advantage to allogenic graft material. This had an additional advantage in that the patient felt less heterogeneity because it originated from the patient's body (Table 1).

Considering the clinical applications of the ATBG, the most important clinical result of using ATBG was that it could be obtained easily with a compact bone structure

Table 1. Advantage of autogenous tooth-bone graft material

Advantage of autogenous tooth bone graft material

No marrow and fat

Simple histology

Low critical infection

Simple processing

Low level of sterility

Age independent

Abundant healthy collagen

DPP (dentin phosphophoryn): Osteopromotion action ${ }^{21)}$ 
because of the favorable composition, as described above. In a previous study, in various clinical situations (Maxillary sinus augmentation, ridge augmentation), it was reported that excellent crestal bone stability could be obtained with new bone and densified lamellated bone formation histologically ${ }^{21,22)}$.

Among the various indications, it appears to have an advantage when used in transmucosal GBR with immediate implantation after extraction and when grafted in a volumetric augmentation with a peri-implant defect ${ }^{20)}$. In particular, in the case of secondary healing (or open healing) without a membrane covering, it healed without infection because of its own tissue affinity even when dehiscence had occurred. The volume as a space maintainer could be maintained by providing a rigid matrix on horizontal bone augmentation ${ }^{20}$. Successful bone regeneration could be achieved by combining particle and block type ATBG in vertical augmentation without a space maintainer, such as titanium mesh ${ }^{23)}$. When ATBG was used as a sinus graft, which generally required a large amount of bone substitute, there was a relatively low bone density at the initial phase but this increased gradually with increasing stability at the long term follow-up ${ }^{24)}$.

The development of ATBG should be toward a combination with computer-guided surgery as well as other bone graft materials. In particular, there is necessary to use the materials to accumulate the surrounding volume with the immediate loading. In this case, the high affinity of the materials with the host tissue was considered to be an important factor in the healing process ${ }^{24}$. Therefore, it appeared that ATBG could be used as a suitable material for maintaining the soft and hard tissue morphology in a jaw defect.

ATBG in current implant dentistry can be summarized as follows.

1. An ATBG has high affinity to soft tissue and osteogenic activity on an extracted socket, periodontal defect and sinus graft without infection.

2. The ATBG can induce rigid bone regeneration on a sinus graft and periodontal augmentation.

3. Successful bone formation around immediate loaded implant can be achieved and ATBG is a suitable bone substitute for digital bone graft.

\section{XENOGRAFT BONE SUBSTITUTES}

Several methods have been used to increase the bone quantity, such as maxillary sinus floor elevation and bone grafting, ridge expansion osteotomy (REO), GBR, onlay and inlay (veneer) bone grafts, socket augmentation, and orthodontics. However, all these procedures are technique-sensitive, and there has been no prospective study on randomized material to estimate the benefit of various procedures. The effects of different materials and techniques in clinical practice are difficult to compare in terms of successful graft operation. There are many factors involved in the treatment of alveolar defects to understand beforehand even though the shape of each alveolar defect might be the most important issue to clinicians. Clinicians should understand possible interactions of these involved factors around the surgical fields, such as origin of growth factors, importance of extracellular matrix, role of inflammatory cells, behavioral science of osteoblast, and macro- and micro-structure of bony substitutes to be used $^{25)}$. Clinicians tend to focus on the clinical results postoperatively, but should have more knowledge of histologic results to compare the differences and prevent unpredictable complications after bone grafting procedures.

From a fundamental point of view, there should be 10 $100 \mathrm{~nm}$ of interface range between the host cell and a particle of bone substitute, and the size of cells ranges 30 50 $\mu \mathrm{m}$ up to hundreds $\mu \mathrm{m}^{26)}$, suggesting new bone formation would not occur in a situation of mobile environment, or in a situation of affluent tissue fluid environment. As the early pioneer companies producing bone substitutes focused on the macroscopic structure of their products similar to human bone, many followers have tried to do the same way and even more so about the microscopic structure. However, it has been known that fabrication of channels, the mesoscopic structure, are more important to help faster angiogenesis and expedite the remodeling process to make the trabecular anastomosis ${ }^{27}$. Which bony substitute is the best? To answer this question, it has been suggested any bony substitute with non-porous surface, high-temperature damaged and glassified surface, and pebbled appearance should not be selected as bone grafting materials.

There are a few environmental factors for clinicians to 
consider before the bone grafting procedure:

1. Opening of wound: consideration whether the wound is open, or closed at the time of surgery.

2. Shape of defect: consideration whether the defect shape is contained type, or non-contained type.

3. Grafting material: consideration whether the grafting material is going to be mixed with the other material, or not.

4. Type of barrier membrane: consideration whether the defect is going to be covered with a resorbable type of membrane, or a non-resorbable type of membrane.

5. Wound closure: consideration whether the wound is going to be open, or closed.

As far as the histologic results after bone grafting procedure are concerned, it is not easy to clearly differentiate good, or bad result compared to the clinical findings from the clinician's viewpoint. Clinicians cannot help but categorizing the certain level of density of the newly-formed tissue when they make an osteotomy because it generally takes a few days to weeks to get the biopsy result. For example, clinicians may be confused to correlate the clinically good, or well findings to the histologically bad, or questionable results in terms of evaluating the long-term prognosis of a certain case. It is highly recommended to pay attention to Kim and Lee's report $(2017)^{28)}$ in order to categorize the different levels of remodeling pattern of the newly-formed tissue. The biopsy results are categorized into one of 5 different remodeling patterns based on the activity level of grafting materials on osteogenic bony induction, the level of mesenchymal organization, the amount of infiltration of inflammatory cells, and the pattern of anastomosing of trabecular bones as shown in Table 2.

In addition to the above-mentioned considering factors, it is definitely recommended to find and make use of patient's own pristine natural bone areas, if any, at all times when a dental implant is placed into the previously augmented site with bone grafting materials. The cases in which the histologic results are not evaluated before implant placement surgery are even more so no matter where the surgical site would be.

There are not many clinicians to be concerned about the physicochemical properties of a certain grafting materials. It may be helpful to check the $\mathrm{pH}$ value of grafting materials before the surgery and to correlate the clinical findings with the $\mathrm{pH}$ value especially in a case that the $\mathrm{pH}$ value is not within the normal range. Ham $(2018)^{27)}$ examined the $\mathrm{pH}$ value of 12 different xenograft bone substitutes including bovine, porcine, and equine origin as test group and 3 different alloplastic bone substitutes as control group. In the report most of bone grafting substitutes available in the market showed somewhat neutral zone of $\mathrm{pH}$ value ranging from 6.79 to 8.07 except the two substitutes, TiOss (Chiyewon, Korea) and Cerabone (Botiss Dental, Germany) showing the relatively higher basic $\mathrm{pH}$ value of 9.80 and 10.32, re-

Table 2. Classification of bone remodeling for implant site development (SK Lee, 2017) ${ }^{28)}$

\begin{tabular}{|c|c|}
\hline Classification & Histological findings \\
\hline Excellent bony remodeling & $\begin{array}{l}\text { 1. Osteogenic bony induction is active } \\
\text { 2. Cancellous bones are anastomosed with thick trabecular bones } \\
\text { 3. Loose connective tissue without infiltration of inflammatory cells }\end{array}$ \\
\hline Favorable bony remodeling & $\begin{array}{l}\text { 1. Osteogenicbony induction is active, but incomplete } \\
\text { 2. Cancellous bones are anastomosed, but immature } \\
\text { 3. Loose connective tissue without infiltration of inflammatory cells }\end{array}$ \\
\hline Partial bony remodeling & $\begin{array}{l}\text { 1. Osteogenic bony induction may be present occasionally and grafting materials rarely produce } \\
\text { new bones } \\
\text { 2. Infiltration of inflammatory cells are seen in stromal tissues }\end{array}$ \\
\hline Degenerative bony remodeling & $\begin{array}{l}\text { 1. No new bone formation is found around the grafting materials } \\
\text { 2. Marked infiltration of chronic inflammatory cells } \\
\text { 3. Stromal fibrous tissue may be edematous and degenerative }\end{array}$ \\
\hline Poor bony remodeling & $\begin{array}{l}\text { 1. The grafting materials do not induce any osteo-inductive effect, nor osteo-conductive effect } \\
\text { on the marrow tissue } \\
\text { 2. Most of grafting materials are scattered and surrounded by fibrous tissue } \\
\text { 3. Sclerotic collagen bundles are deposited and the stromal fibrosis may be severe to encircle } \\
\text { and separate the grafting materials } \\
\text { 4. Throughout the lesion there is no evidence of inflammatory reaction }\end{array}$ \\
\hline
\end{tabular}


Table 3. The $\mathrm{pH}$ value of various alloplastic and xenograft bone substitutes which are available in Korea

\begin{tabular}{|c|c|c|c|c|}
\hline $\begin{array}{l}\text { Product Name } \\
\text { (type) }\end{array}$ & Donor & Origin & Company & $\begin{array}{c}\mathrm{pH} \text { average } \\
(\mathrm{pH} \text { experimental 1/ } \\
\text { experimental 2) }\end{array}$ \\
\hline OSTEON (GBG0510) & Alloplast & Bioactive $\beta$-TCP coating (HA: $\beta-\mathrm{TCP}=70: 30$ ) & GENOSS & $7.10(7.09 / 7.11)$ \\
\hline $\begin{array}{l}\text { OSTEON II } \\
\text { (DTT70G0510200) }\end{array}$ & Alloplast & $\begin{array}{l}\text { Synthetic bone grafting material } \\
(\mathrm{HA}: \beta-\mathrm{TCP}=30: 70)\end{array}$ & GENOSS & $7.01(6.90 / 7.11)$ \\
\hline $\begin{array}{l}\text { OSTEON III } \\
\text { (3G0510050) }\end{array}$ & Alloplast & $\begin{array}{l}\text { Ca-P coated bone grafting material } \\
(\mathrm{HA}: \beta-\mathrm{TCP}=60: 40)\end{array}$ & GENOSS & $7.28(7.30 / 7.28)$ \\
\hline OCS-H (4-0210-025) & Equine & Natural bovine bone & Nibec & $7.61(7.63 / 7.59)$ \\
\hline $\begin{array}{l}\text { THE Graft } \\
(\text { TG-A05(0.5cc)) }\end{array}$ & Porcine & Porcine base, cancellous granules & Purgo & $7.28(7.26 / 7.29)$ \\
\hline InterOss (IOSG050) & Bovine & Natural bovine bone & SigmaGraft & $7.99(7.97 / 8.01)$ \\
\hline Ti-Oss (25-0512) & Bovine & Natural bovine bone & Chiyewon & $\begin{array}{l}\text { Old (product 2011-09-07): } \\
9.80(9.79 / 9.81) \\
\text { New (product 2014-06-27): } \\
7.20(7.20 / 7.19)\end{array}$ \\
\hline OssCon-G (REF G5025) & Bovine & Spongious bone & ALLSBIOMED & $8.07(8.02 / 8.12)$ \\
\hline A-Oss (BBSO2) & Bovine & Natural bovine bone & Osstem & $7.61(7.67 / 7.55)$ \\
\hline OCS-B (1-0210-025) & Bovine & Natural bovine bone & Nibec & $7.74(7.76 / 7.71)$ \\
\hline $\begin{array}{l}\text { InduCera Dual Coat } \\
\text { (REF 3201) }\end{array}$ & Bovine & Ca-P coated deproteinated bovine bone powder & Oscotec & $6.79(6.80 / 6.77)$ \\
\hline BioCera (REF 1106) & Bovine & Ca-P coated deproteinated bovine bone powder & Oscotec & $7.01(7.01 / 7.01)$ \\
\hline $\begin{array}{l}\text { Bio-Oss } \\
\text { (Geistlich Bio-Oss) }\end{array}$ & Bovine & Spongious bone & Geistlich & $7.75(7.75 / 7.75)$ \\
\hline Cerabone (REF 1510) & Bovine & Natural bovine bone & Botiss dental & $10.32(10.31 / 10.33)$ \\
\hline
\end{tabular}

spectively (Table 3).

Biopsy samples obtained from clinical cases of bone substitutes with relatively higher basic $\mathrm{pH}$ value showed no evidence of new bone formation and the fibrous stroma was severely degenerated in the absence of host reaction, i.e., inflammation. It is interesting to look at bubbled appearances and severely sclerosed fibrous tissue without inflammatory reaction in the biopsy samples of one case where collagenous foreign material, Gelfoam (Pfizer, USA) was used to preserve the socket profile immediately after tooth extraction. Some surgeons have insisted that it would be better to put a collagenous material into the extraction socket to preserve the soft tissue profile so that they could place a dental implant in $4 \sim 8$ weeks and do the bone grafting procedure easily at the same time, if necessary. However, there is no research data showing differences between a wide variety of collagenous materials to choose in the market.

As far as the surgical techniques are concerned, it has been recommended that surgeons need to focus on two things, angiogenesis and wound stabilization. Bleeding is definitely necessary for the healing process, but hemorrhage is not good because the tissue wants to be stable.
Therefore, wound stabilization is the most important factor, but any activity of high pressure onto the grafting materials is not recommended not only because the grafted area needs spaces of stromal tissue, but also because the channels, mesoscopic structures for angiogenesis in the bone grafting materials may be broken.

Nowadays bony substitutes from animal origin have been widely used in the dental field without any clinical event to augment a small socket defect, a huge vertical and horizontal defect, and a maxillary sinus ${ }^{31)}$ as implant site development. Nonetheless clinicians should select any xenograft material with a lot of good clinical and histological documentations. It can be used solely to augment the intra-oral defect ${ }^{27}$, or mixed with the other type of bone substitutes, or autogenous bones ${ }^{30)}$ depending on shape, size, location of the defect.

In conclusion, it goes without saying that xenograft bone substitutes can be selected as one of good candidates of bone grafting materials to augment the intra-oral bony defects. 


\section{ALLOPLASTIC GRAFT BONE SUBSTITUTES}

Alloplastic grafts have been used increasingly because of their excellent productivity and function as a scaffold with the development of the growth factors. This chapter reviews the requirement of an alloplastic graft, application of clinical practice, limitation of the graft, and development of a future oriented to overcome these limitations.

\section{Requirement of alloplastic graft}

According to the consensus proposed by the World Congress of Biomaterial, the requirement for an alloplastic graft are as follows ${ }^{32}$.

- Interconnected macro-porosity

- Surface micro-roughness

- Combination of Beta-TCP, HA, Calcium silicate

\section{Characteristics and variety of alloplastic grafts}

Alloplastic bone was developed in various ways from manufacture to microstructure. An example of their de-

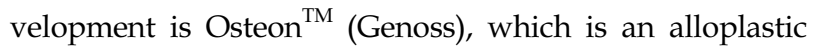
bone material made in Korea. Osteon I (initial model of Osteon), corresponding to the hydroxyapatite (HA) scaffold made using the replica method, showed $77 \%$ porosity with a 300 to $500 \mu \mathrm{m}$ pore size. This was released with a tricalcium phosphate (TCP) coating and showed excellent properties in block form but had limited to use in particulate form.

Osteon II altered to a reinforced microstructure with inter-connective porosity and small pore size of $<250$ $\mu \mathrm{m}$. This was called a biphasic scaffold $(\mathrm{HA}+\beta-\mathrm{TCP})$ made using the sacrificial template method including 70\% of resorbable TCP. On the other hand, it was difficult to remove the impurities in the manufacturing process completely; hence, further improvement is necessary. The next step, Osteon III, was the same biphasic scaffold that was manufactured with improved bone formation using a simpler air-bubble technique.

In a clinical view, long-term maturation is important for an alloplastic bone graft. In the first generation (Osteon I), there was a good outcome with a block-form graft, which showed a stable result in maintaining the volume with a non-resorbable composition of $\mathrm{HA}^{27}$. On the other hand, the second generation (osteon II) was developed because the first generation was difficult to use in particulate form. Osteon II could be used in particulate form from socket preservation to sinus graft and ridge augmentation. The material was a biphasic scaffold, which was a combination of HA and $\beta$-TCP. The material had low radiopacity at the initial phase but the density increased to the crest part $^{33)}$. In view of the volume, however, Osteon II showed a decreased aspect compared to the first generation because of the composition of $\beta$-TCP. This could be overcome easily by over build-up by as much as the anticipated absorption ${ }^{34)}$. To prevent this absorption tendency, the relative proportion of HA increased with a change in the manufacturing process when developing the next generation.

In the third generation (Osteon III), the composition of $60 \%$ of HA and $40 \%$ of $\beta$-TCP with enhanced inter-connectivity was changed to higher porosity and interconnection. The particulate form of osteon III showed excellent interconnectivity and increased crystallinity caused by an increase in sintering temperature to overcome the lower strength. The material showed excellent scaffold properties in terms of its osteoblast and osteoclast activity compared to a conventional alloplastic bone graft in an animal (rabbit calvaria) study ${ }^{34}$. In a dog model, excellent bone regeneration could be obtained from a combination of resorbable membrane (BioGide ${ }^{\mathbb{R}}$ ) and alloplastic graft compared to a xenograft $\left(\text { Bio-Oss }{ }^{\mathbb{R}}\right)^{35)}$. Therefore, good results could be achieved in not only horizontal and vertical GBR, but also in peri-implantitis without a membrane using Osteon III only, which had the advantages of excellent interconnective porosity ${ }^{34)}$.

\section{Clinical applications and limitation of alloplastic graft}

Conventionally, the application of an alloplastic graft has been limited only to small or contained defects due to the lack of osteoinductivity. The long-term outcome of forming functional bone needs to be determined. In particular, the particle size plays an important role in an alloplastic graft. If the size is too small, it might affect the absorption of the adjacent tissue during the modeling period. A size of 0.5 to $1 \mathrm{~mm}$ was found to be most suitable $^{34)}$. Because of its disadvantage of moldability com- 
pared to other bone substitutes, it was manufactured by combining porcine collagen, which might be absorbed within 2 weeks and the size of the alloplastic graft was limited to 0.5 to $1 \mathrm{~mm}$. Contouring augmentation could be considered as an indication of an alloplastic bone graft for a sufficient volume because of its excellent moldability and volumetric stability. Excellent results of socket preservation $^{36)}$ and sinus graft ${ }^{33)}$ with an alloplastic graft have been reported in many studies. Alloplastic grafts have been used continuously because of their advantages of bioabsorption and replacement with autogenous bone over a long-term period $^{35,36)}$.

Contouring augmentation can be divided into two methods: covering with a collagen membrane or without a membrane (direct application to the graft sites without hydration). In the past, the procedure was performed mainly without a membrane, but recently, the membrane has been used widely for wound stability ${ }^{34)}$. Even in an alloplastic graft, each graft showed different advantages according to their composition. A higher rate of bone formation was observed in particulate bone composited with collagen rather than that with a particular shape ${ }^{34)}$. Therefore, the recently recommended protocol was to apply Osteon III on the first layer adjacent to the implant below the contour augmentation with Osteon III collagen and cover the grafts with a membrane ${ }^{27}$. The collagen-enriched bone showed slow osteogenesis, approximately 1.5 times, but excellent volumetric stability. The application range of alloplastic bone graft has been increasing, such as ridge augmentation, in which the collagen-enriched bone covering the membrane is built up using an implant fixture as a tenting effect with a long healing period ${ }^{34)}$.

\section{Development of future alloplastic graft}

Alloplastic grafts have been also developed in the form of block bone, which can be used as a tenting role with a screw on augmentation for large defects. In this case, it should be manufactured in such a way that allows easy trimming, drilling, and screw fixation for operability. Many grafts have been developed with a collagen coating for these reasons. In addition, it would be necessary to develop an anchoring device, such as a screw type because the fixation of alloplastic block bone is more difficult with a conventional screw than with autogenous block bone.
A 3D printed bone graft is expected if the technology advances one step further and a customized design could be available based on the CT data for various alveolar defects through alloplastic graft materials. A reinforced customized graft structure with sintering could be obtained after 3D printing ${ }^{34)}$. To overcome the limitations of an alloplastic graft, many attempts have been to enhance bone quality by adding DNA or glycoprotein. The addition of components, such as polydeoxyribonucleotide (PDRN), which is DNA with an anti-ischemic and anti-inflammatory function, could accelerate the healing process on angiogenesis. A recent rabbit calvaria study revealed the possibility of accelerating regeneration but the effect was less than that of rhBMP- ${ }^{7}$. The development of customized grafts combined with these growth factors could be the right direction. Additional accumulated data with technological development will be needed before this type of graft can be used clinically.

\section{CONCLUSION}

Each bone substitute material developed thus far has its advantages and disadvantages. Despite the rapid technological developments, there is no material manufactured that combines all the advantages of various materials. The actual process of maturation, which is the most fundamental part of clinical applications after each graft, has been studied by clinicians with different preferences when selecting the type of bone substitutes. In addition, clinicians have been supplementing the disadvantages of the preferred bone substitute through an appropriate operation method (transmucosal or submerged GBR, membranous or non-membranous technique). The decision of a treatment plan is always important regardless of the bone substitute type. Although it is difficult to characterize the properties of all bone substitutes accurately, it is important to identify the progress of technology and the advantages/disadvantages of each type of bone substitute. All bone graft procedures should be used to better predict the long-term success of dental implants. This consensus report suggests that basic surgical principles, such as the choice of appropriate materials and the provision of an adequate healing period, be adhered to. 


\section{CONFLICT OF INTEREST}

The authors reported no conflicts of interest related to this study.

\section{ORCID}

Jong-Ho Lee, https://orcid.org/0000-0002-8843-545X

Jeong Keun Lee, https://orcid.org/0000-0002-5561-6297

Jeong-Kui Ku, https://orcid.org/0000-0003-1192-7066

\section{REFERENCES}

1. Lee SK, Lee JK, Oh SH, Ham BD, Chung SM. Bone Grafts for Implant Dentistry. Kim YK (Chairman). Conference conducted by The Korean Academy of Implant Dentistry, Seoul, Korea. 2018, october.

2. Pandit N, Pandit I. Autogenous bone grafts in periodontal practice: A literature review. Journal of the International Clinical Dental Research Organization 2016;8:27-33.

3. Schlegel KA, Zimmermann R, Thorwarth M, et al. Sinus floor elevation using autogenous bone or bone substitute combined with platelet-rich plasma. Oral surgery, oral medicine, oral pathology, oral radiology, and endodontics 2007;104: e15-25.

4. Sakkas A, Wilde F, Heufelder M, Winter K, Schramm A. Autogenous bone grafts in oral implantology-is it still a "gold standard"? A consecutive review of 279 patients with 456 clinical procedures. Int J Implant Dent 2017;3:23.

5. Lee JH. Long term results of Implantation combined with autogenous bone source. Kim YK (Chairman), Bone Grafts for Implant Dentistry. The Korean Academy of Implant Dentistry 2018;37:12.

6. Lundgren S, Rasmusson L, Sjostrom M, Sennerby L. Simultaneous or delayed placement of titanium implants in free autogenous iliac bone grafts. Histological analysis of the bone graft-titanium interface in 10 consecutive patients. Int J Oral Maxillofac Surg 1999;28:31-37.

7. Cordaro L, Amade DS, Cordaro M. Clinical results of alveolar ridge augmentation with mandibular block bone grafts in partially edentulous patients prior to implant placement. Clinical oral implants research 2002;13:103-11.

8. Nyström E, Ahlqvist J, Gunne J, Kahnberg KE. 10-year follow-up of onlay bone grafts and implants in severely resorbed maxillae. International Journal of Oral and Maxillofacial Surgery 2004;33:258-62.

9. Acocella A, Bertolai R, Colafranceschi M, Sacco R. Clinical, histological and histomorphometric evaluation of the healing of mandibular ramus bone block grafts for alveolar ridge augmentation before implant placement. J Craniomaxillofac Surg 2010;38:222-30.

10. Misch CM, Misch CE, Resnik RR, Ismail YH. Reconstruction of maxillary alveolar defects with mandibular symphysis grafts for dental implants: a preliminary procedural report. The International journal of oral \& maxillofacial implants 1992;7: 360-66.

11. Sjostrom M, Sennerby L, Nilson H, Lundgren S. Reconstruction of the atrophic edentulous maxilla with free iliac crest grafts and implants: a 3-year report of a prospective clinical study. Clinical implant dentistry and related research 2007;9:46-59.

12. Galindo-Moreno P, León-Cano A, Ortega-Oller I, Monje A, O'Valle $\mathrm{F}$, Catena A. Marginal bone loss as success criterion in implant dentistry: beyond $2 \mathrm{~mm}$. Clinical oral implants research 2015;26:e28-e34.

13. Levin L, Nitzan D, Schwartz-Arad D. Success of dental implants placed in intraoral block bone grafts. Journal of periodontology 2007;78:18-21.

14. Schwartz-Arad D, Ofec R, Eliyahu G, Ruban A, Sterer N. Long Term Follow-Up of Dental Implants Placed in Autologous Onlay Bone Graft. Clinical implant dentistry and related research 2016;18:449-61.

15. Saghiri MA, Asatourian A, Sheibani N. Angiogenesis in regenerative dentistry. Oral Surg Oral Med Oral Pathol Oral Radiol 2015;119:122.

16. Barone A, Toti P, Quaranta A, et al. Volumetric analysis of remodelling pattern after ridge preservation comparing use of two types of xenografts. A multicentre randomized clinical trial. Clinical oral implants research 2016;27:e105-e115.

17. Felisati G, Saibene AM, Lenzi R, Pipolo C. Late recovery from foreign body sinusitis after maxillary sinus floor augmentation. BMJ Case Reports 2012;2012:bcr2012007434.

18. Kim YK, Kim SG, Byeon JH, et al. Development of a novel bone grafting material using autogenous teeth. Oral surgery, oral medicine, oral pathology, oral radiology, and endodontics 2010;109:496-503.

19. Gomes MF, dos Anjos MJ, Nogueira TO, Guimaraes SA. Histologic evaluation of the osteoinductive property of autogenous demineralized dentin matrix on surgical bone defects in rabbit skulls using human amniotic membrane for guided bone regeneration. The International journal of oral \& maxillofacial implants 2001;16:563-71.

20. Park SS, Kim SG, Lim SC, Ong JL. Osteogenic activity of the mixture of chitosan and particulate dentin. Journal of biomedical materials research. Part A 2008;87:618-23.

21. Deshpande AS, Fang PA, Zhang X, Jayaraman T, Sfeir C, Beniash E. Primary structure and phosphorylation of dentin matrix protein 1 (DMP1) and dentin phosphophoryn (DPP) uniquely determine their role in biomineralization. Biomacromolecules 2011;12:2933-45.

22. Park SM, Um IW, Kim YK, Kim KW. Clinical application of auto-tooth bone graft material. J Korean Assoc Oral Maxillofac Surg 2012;38:2-8.

23. Lee JY, Kim YK, Yi YJ, Choi JH. Clinical evaluation of ridge augmentation using autogenous tooth bone graft material: case series study. Journal of the Korean Association of Oral and Maxillofacial Surgeons 2013;39:156-60.

24. Oh SH. Easy Implant Bone Grafts Using Auto Tooth Bone Paste. Kim YK (Chairman), Bone Grafts for Implant Dentistry. The Korean Academy of Implant Dentistry 2018;37 (Supple 2):13. 
25. Curry AS, Pensa NW, Barlow AM, Bellis SL. Taking cues from the extracellular matrix to design bone-mimetic regenerative scaffolds. Matrix biology : journal of the International Society for Matrix Biology 2016;52-54:397-412.

26. Figueiredo M, Henriques J, Martins G, Guerra F, Judas F, Figueiredo $\mathrm{H}$. Physicochemical characterization of biomaterials commonly used in dentistry as bone substitutes-comparison with human bone. Journal of biomedical materials research. Part B, Applied biomaterials 2010;92:409-19.

27. Ham BD. Clinical and Histological Analysis of Different Types of Xenograft Bone Substitute for Alveolar Ridge Augmentation. Kim YK (Chairman), Bone Grafts for Implant Dentistry. . The Korean Academy of Implant Dentistry 2018;37 (supple 2):14.

28. Kim YS, Lee SK. Histological observation of excellent bony remodeling in xenogenic bone graft for dental implant. The Korean Journal of Oral and Maxillofacial Pathology 2017;41: 17-26.

29. Cosyn J, Cleymaet R, De Bruyn H. Predictors of Alveolar Process Remodeling Following Ridge Preservation in High-Risk Patients. Clin Implant Dent Relat Res 2016;18:226-33.

30. Meloni SM, Jovanovic SA, Urban I, Canullo L, Pisano M, Tallarico M. Horizontal Ridge Augmentation using GBR with a Native Collagen Membrane and 1:1 Ratio of Particulated Xenograft and Autologous Bone: A 1-Year Prospective Clinical Study. Clin Implant Dent Relat Res 2017;19:38-45.

31. Froum SJ, Wallace SS, Cho SC, Elian N, Tarnow DP. Histomorphometric comparison of a biphasic bone ceramic to anor- ganic bovine bone for sinus augmentation: 6- to 8-month postsurgical assessment of vital bone formation. A pilot study. The International journal of periodontics \& restorative dentistry 2008;28:273-81.

32. Williams DF, Black J, Doherty PJ. Second consensus conference on defintions in biomaterials, in Dohery PJ et al. (Eds). Biomaterial-Tissue interfaces. Advances in Biomaterials. 1992;10, Elsevire, Amsterdam:525.

33. Chiu TS, Lee CT, Bittner N, Prasad H, Tarnow DP, Schulze-Spate U. Histomorphometric Results of a Randomized Controlled Clinical Trial Studying Maxillary Sinus Augmentation with Two Different Biomaterials and Simultaneous Implant Placement. The International journal of oral \& maxillofacial implants 2016;33:1320-30.

34. Chunh SM. Hard tissue regeneration with synthetic scaffold Synthetic(CaP) Bone. Kim YK (Chairman), Bone Grafts for Implant Dentistry. The Korean Academy of Implant Dentistry 2018;37 (supple 2):15.

35. Lee IK, Lim HC, Lee JS, Hong JY, Choi SH, Jung UW. Layered approach with autogenous bone and bone substitute for ridge augmentation on implant dehiscence defects in dogs. Clinical oral implants research 2016;27:622-8.

36. Mayer Y, Zigdon-Giladi H, Machtei EE. Ridge Preservation Using Composite Alloplastic Materials: A Randomized Control Clinical and Histological Study in Humans. Clin Implant Dent Relat Res 2016;18:1163-70. 